\title{
Combined p53/Bax mutation results in extremely poor prognosis in gastric carcinoma with low microsatellite instability
}

\author{
A Mrózek1, H Petrowsky ${ }^{\text {, }}$ I Sturm ${ }^{1}$, J Kraus ${ }^{2}$, S Hermann ${ }^{1}$, \\ S Hauptmann², M Lorenz ${ }^{3}$, B Dörken ${ }^{1}$ and PT Daniel ${ }^{*, 1}$ \\ ${ }^{1}$ Department of Hematology, Oncology and Tumor Immunology, University \\ Medical Center Charité, Humboldt University, Berlin, Germany \\ ${ }^{2}$ Institute of Pathology, Charité, Humboldt University, Berlin, Germany \\ ${ }^{3}$ Department of General and Vascular Surgery, University Hospital, Johann \\ Wolfgang Goethe University, 60590 Frankfurt am Main, Germany \\ * Corresponding author: PT Daniel, Molecular Hematology and Oncology, \\ Charité-Campus Berlin-Buch, Humboldt University, Lindenberger Weg 80, \\ 13125 Berlin-Buch, Germany. Tel: +49-30-9417-1644; \\ Fax: +49-30-9417-1644; E-mail: pdaniel@ mdc-berlin.de
}

Received 8.8.02; accepted 17.9.02

Edited by V De Laurenzi

\section{Introduction}

Gastric cancer has a poor prognosis and remains the second common cause of cancer-related deaths worldwide. Although the incidence of gastric cancer is declining, the mortality because of stomach cancer is ranking fourth among different cancers in the European Union and accounts for $7 \%$ of cancer-related death in males and $5 \%$ in females. ${ }^{1-3}$ The only chance for cure is early and complete surgical resection including adjacent lymph nodes, ${ }^{4}$ which results in Europe in a 5 -year survival rate of roughly $20 \%$. This reflects the fact that gastric cancer recurs in $80 \%$ of cases despite 'curative' gastrectomy and displays an extreme resistance to cytotoxic, DNA-damaging anticancer therapies. This highlights the need for a better understanding of disease pathogenesis and progression to improve therapeutic outcome.

We have shown previously that the analysis of apoptosis signaling pathways is a suitable approach to identify patients with a good or extremely poor prognosis. In this line, we were the first to describe a defect in the expression of the proapoptotic Bax protein in breast cancer, ${ }^{5}$ compared with the nonmalignant breast epithelium. Re-expression of Bax in breast cancer cell lines reduced tumor growth in nude mice. ${ }^{6}$ The complete loss of Bax results in resistance to some but not all apoptosis stimuli including anticancer drugs. ${ }^{7-9}$ Likewise, overexpression of the Bax homolog Bak or the BH3-only protein Nbk/Bik counteracts acquired drug resistance. $^{10}$

Furthermore, we and others showed that reduced Bax expression is a negative prognostic factor and correlates with a shorter overall survival in patients with breast, ${ }^{11}$ ovarian, ${ }^{12}$ colorectal, ${ }^{13,14}$ esophageal ${ }^{15}$ and pancreatic cancer. ${ }^{16}$ In childhood acute lymphoblastic leukemia (ALL), the loss of Bax protein expression is associated with chemoresistant relapse and a defective activation of the caspase cascade. $^{17}$

The tumor suppressor gene p53 is a transcriptional activator of the Bax gene ${ }^{18}$ and both genes act in the same signaling cascade to trigger the mitochondrial apoptosis pathway. ${ }^{19-21}$ In fact, we observed that the deregulated expression of wild-type p53 protein in follicular thyroid carcinoma coincides with increased expression of the p53 target genes p21 ${ }^{\mathrm{CIP} / \mathrm{WAF}-1}$ and Bax. ${ }^{22}$ Nevertheless, the loss of $\mathrm{Bax}$ is associated with a poor prognosis independent of the p53 gene mutation status in metastatic or locally advanced colorectal cancer. ${ }^{13,14}$ Inactivation of Bax by mutation has been shown to be restricted to tumors with defects in DNA mismatch repair (MMR). ${ }^{14,23}$ Loss of Bax expression occurs, however, in consequence of disturbed transcriptional regulation in the vast majority of cancers. ${ }^{5,7,14,15,17,24}$

Thus, no concise data were so far available regarding the consequences of p53 and Bax inactivation by mutation on

\footnotetext{
Abbreviations: MSI, microsatellite instability; MMR, mismatch repair; $\mathrm{BH}, \mathrm{Bcl}-2$ homology domain; $\mathrm{ALL}$, acute lymphoblastic leukemia; CLL, chronic lymphocytic leukemia; SI, staining index; SSCP-PCR, single-stranded conformational polymorphism-polymerase chain reaction
} 
disease prognosis in gastric and other gastrointestinal tumors. In this study, we therefore examined the inactivation of the p53 and Bax gene in a group of 116 patients with R0-resected, sporadic gastric cancer to determine the influence of these regulators on tumor biology and disease prognosis.

Surprisingly and unlike the situation in other tumors, we observed that loss of Bax expression is paradoxically associated with better prognosis in gastric cancer. This was even more evident when the tumors were analyzed for Bax $\mathrm{G}(8)$ tract frameshift mutations as underlying cause for the loss of Bax protein expression. Thus, the presence of such Bax-frameshift mutation identifies patients with a better disease prognosis. This also suggests that such tumors may share, apart from a different tumor biology, a different mode of pathogenesis as suggested previously for MMR-deficient tumors. Nevertheless, the analysis of the microsatellite markers BAT-25 and BAT-26 that identify with high specificity tumors expressing high microsatellite instability (MSI), that is, global MMR deficiency, showed that Bax mutations do not cluster in BAT-25/BAT-26 microsatellite instable tumors. In conclusion, inactivation of Bax by frameshift mutation occurs in tumors with low MSI, which supports our hypothesis of a different tumor biology of this population. Moreover, this is the first report to demonstrate that the additional inactivation of p53 in these Bax-frameshift-mutated tumors is associated with a very aggressive clinical course and an extremely poor prognosis. Altogether, this indicates that additional genetic events such as p53 inactivation may represent a key event in tumor progression in tumors with disturbed MMR, especially in those tumors displaying inactivating mutations in the Bax gene.

\section{Results}

\section{Bax expression and mutation}

We analyzed tumor samples of patients who underwent R0resection (tumor-free resection margins upon pathology review) of sporadic gastric carcinoma with a curative intent. Clinicopathological data are shown in Table 1. At the end of the follow-up period, 33 from 116 (28.4\%) patients survived. Median follow-up after gastric resection for the 33 censored patients was 60.9 months (range 26-131). For the whole group, the median overall survival was 28.6 months.

In contrast to our findings in other disease entities we observed that loss of Bax expression was related to a slightly better prognosis in this cohort of patients with gastric cancer (Figure 1a, log-rank (Mantel-Cox) test: $P=0.19$; not significant).

Previous reports demonstrated that Bax protein expression may be impaired in gastrointestinal cancers with MMR deficiency because of a frameshift mutation in a $G(8)$ tract in exon 3 of the Bax gene. For the analysis of Bax-frameshift mutations, we performed a fragment-length analysis of PCR products encompassing the $\mathrm{G}(8)$ tract as previously described. ${ }^{14}$ We analyzed 99 out of 116 tumors for the presence of Bax-frameshift mutations. In the remaining samples, quality of PCR-products was not sufficient for the fragment-length analysis. Out of $99,18(18.2 \%)$ tumors showed a frameshift
Table 1 Clinicopathological characteristics for all patients $(n=116)$ and the subgroup of Bax-mutated patients $(n=18)$

\begin{tabular}{|c|c|c|}
\hline & $\begin{array}{l}\text { All patients } \\
\qquad n=116\end{array}$ & $\begin{array}{c}\text { Bax-frameshift } \\
\text { mutated } \\
n=18\end{array}$ \\
\hline Male/female & $69 / 47$ & $7 / 11$ \\
\hline Age (in years) & & \\
\hline Median & 63.9 years & 70.6 years \\
\hline Range & (25-91 years) & (34 years) \\
\hline \multicolumn{3}{|l|}{ T-stage of primary tumor } \\
\hline $\mathrm{T} 1$ & 12 & 4 \\
\hline $\mathrm{T} 2$ & 50 & 9 \\
\hline T3 & 49 & 5 \\
\hline $\mathrm{T} 4$ & 5 & 0 \\
\hline \multicolumn{3}{|l|}{ Lymph node status } \\
\hline No & 53 & 9 \\
\hline $\mathrm{N} 1$ & 25 & 5 \\
\hline $\mathrm{N} 2$ & 38 & 4 \\
\hline \multicolumn{3}{|l|}{ Grading } \\
\hline G1 & 11 & 2 \\
\hline G2 & 55 & 10 \\
\hline G3 & 50 & 6 \\
\hline \multicolumn{3}{|l|}{ Histological type } \\
\hline Adenocarcinoma & 73 & 12 \\
\hline Signet-ring cell carcinoma & 33 & 6 \\
\hline Mixed & 10 & 0 \\
\hline \multicolumn{3}{|l|}{ UICC stage } \\
\hline la & 10 & 3 \\
\hline $\mathrm{lb}$ & 28 & 6 \\
\hline II & 25 & 4 \\
\hline Illa & 24 & 2 \\
\hline IIIb & 17 & 3 \\
\hline IV & 12 & 0 \\
\hline \multicolumn{3}{|l|}{ Lauren classification stage } \\
\hline Diffuse & 40 & 6 \\
\hline Intestinal & 65 & 10 \\
\hline Mixed & 11 & 2 \\
\hline \multicolumn{3}{|l|}{ Localization } \\
\hline Cardia & 30 & 3 \\
\hline Fundus & 7 & 1 \\
\hline Corpus & 40 & 4 \\
\hline Antrum & 39 & 10 \\
\hline
\end{tabular}

mutation in the $\mathrm{G}(8)$ tract of Bax gene, leading to the formation of a truncated, nonfunctional Bax protein. Only deletions and no insertions in the $\mathrm{G}(8)$ tract were observed. Most Baxframeshift-mutated tumors presented as localized stage tumors ( $72 \%$ in UICC stages I and II), and $56 \%$ were localized in the antrum ( $\chi^{2}$ test and Fisher's exact test: $\left.P>0.05\right)$. Figure $1 \mathrm{~b}$ shows that patients with tumors carrying a Bax-frameshift mutation have a better overall survival. In gastrointestinal carcinomas, such Bax $\mathrm{G}(8)$ frameshift mutations are known to be caused by MMR deficiency. Thus, the paradoxically better clinical course in Bax-mutated tumors is well in line with the known overall better prognosis of patients with MMR-deficient tumors. ${ }^{25,26}$ Figure 1c confirms that Bax mutation was associated with lower Bax expression in the tumors (MannWhitney $U$-test: $P=0.0079$ ). 

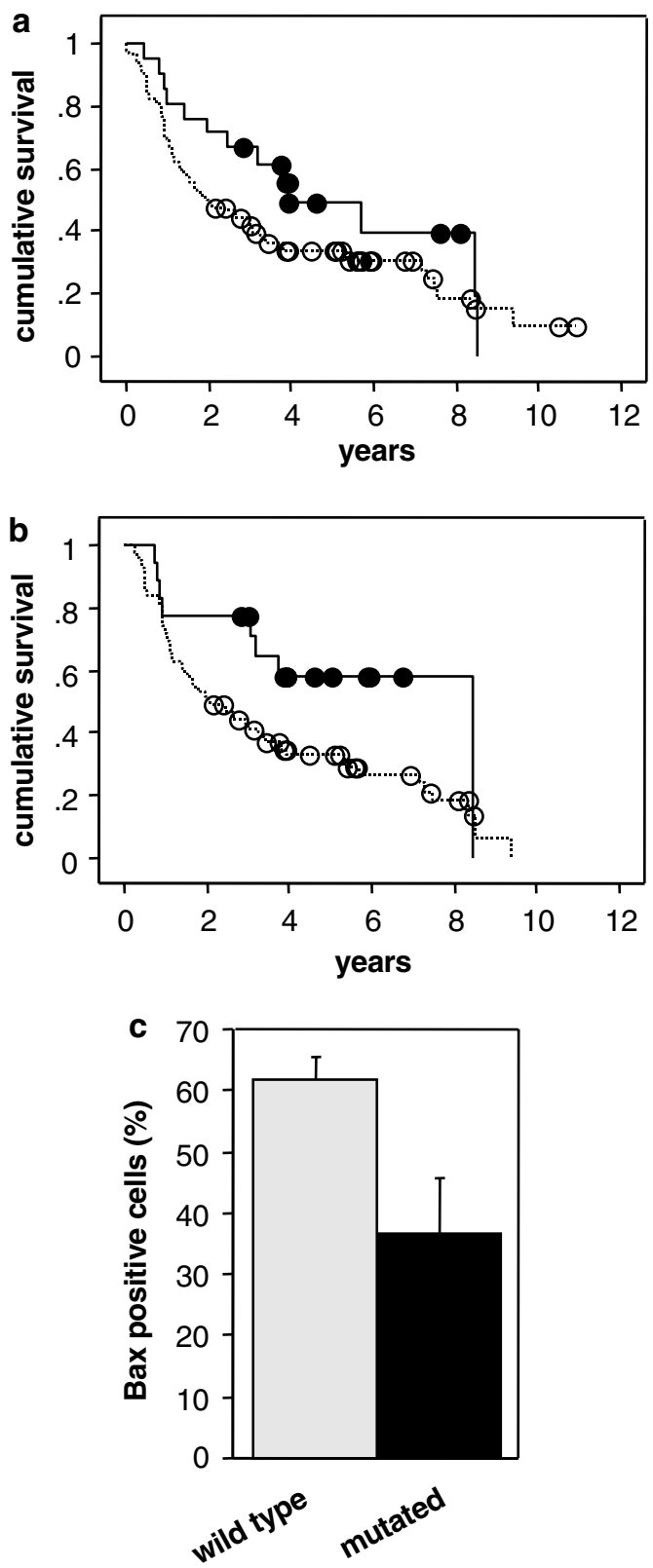

Figure 1 Bax expression and mutation in gastric cancer. Kaplan-Meier analysis of overall survival. (a) Patients were grouped in Bax positive (black circles, continuous line) and Bax negative (open circles, broken line; log-rank (Mantel-Cox) test: $P=0.19$ ) or (b) Bax wild type (open circles, broken line) versus Bax mutated (black circles, continuous line; frameshift mutation in the G8 tract of exon 3; log-rank (Mantel-Cox) test: $P=0.048$ ). (c) Bax mutation is associated with lower percentage of Bax protein expressing cells (Mann-Whitney U-test: $P=0.0079$; mean values \pm S.E.M. are shown)

\section{p53 status and Bax expression and mutation}

Apart from defining the impact of Bax mutation on Bax expression, we were interested in the role of p53, a transcriptional activator of the Bax gene and upstream activator of mitochondrial apoptosis. ${ }^{18}$ Analysis of the p53 gene by single-stranded conformational polymorphism-polymerase chain reaction (SSCP-PCR) analysis of the exons 5-8 detected p53 mutations in 24 of 110 primary tumors $(21.8 \%)$.
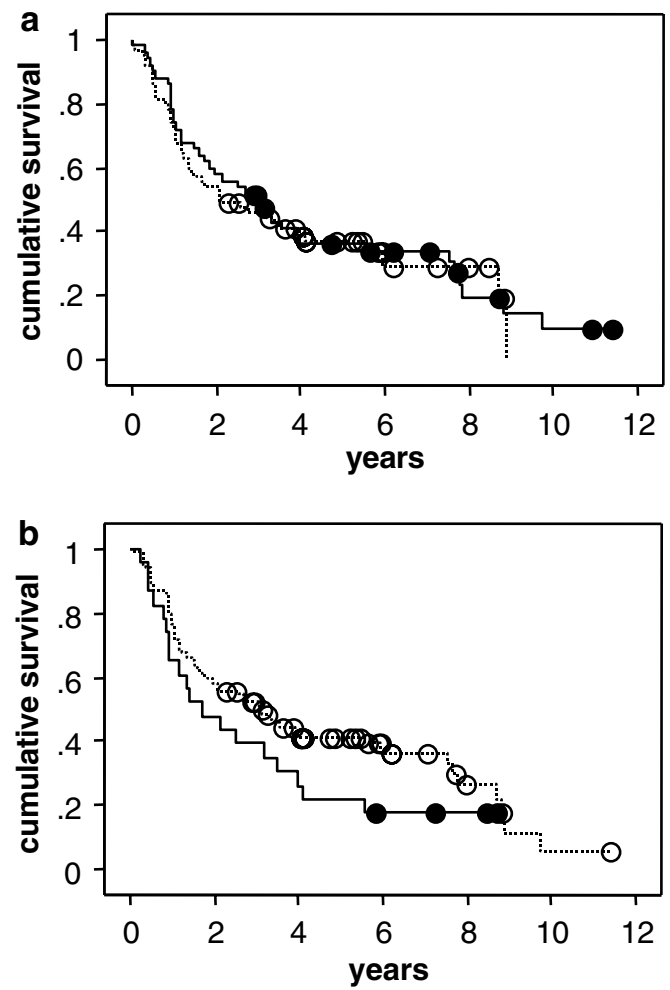

Figure 2 p53 Overexpression and p53 mutation in gastric cancer. KaplanMeier analysis of overall survival. (a) Patients were grouped in p53 positive (black circles, continuous line) and p53 negative (open circles, broken line; log-rank (Mantel-Cox) test: $P=0.71$ ) or (b) p53 wild type (open circles, broken line) versus p53 mutated (black circles, continuous line; log-rank (Mantel-Cox) test: $P=0.075)$

In the remaining cases, tumor DNA was not of sufficient quality to reliably analyze the samples for p53 SSCP-PCR upon two occasions. Altogether, 26 mutations were detected in the tumors: nine in exon 6, nine in exon 7, eight in exon 8. Two tumors exhibited mutations in two exons. In addition, overexpression of p53 was analyzed by immunohistochemistry. As shown in Figure 2a, there was no significant correlation between overall survival and p53 expression levels (log-rank test: $P=0.71$ ). Likewise, the presence of p53 mutations did not significantly discriminate between good or poor disease prognosis (Figure 2b). Patients with p53mutated tumors showed a slightly worse overall survival as compared with the wild-type group, which, however, failed to reach significance (log-rank test: $P=0.075$ ). There was no significant correlation between p53 and Bax mutation (Table 2; $\chi^{2}$ test: $P>0.99$ ) indicating that both events are independent. As described previously in other tumor entities, ${ }^{7,14,15}$ there was no correlation between p53 mutation and the level of Bax protein expression, which corroborates that additional factors, apart from p53, regulate this proapoptotic factor (Mann-Whitney U-test: $P>0.99$ ).

\section{p53 mutation in Bax wild-type versus mutated tumors}

In contrast to the negative findings when assessing p53 mutation in the whole patient cohort, we observed a significant 
Table 2 Relation of Bax and p53 mutation*

\begin{tabular}{lccc}
\hline & Bax wild type & Bax mutation & Total \\
\hline p53 wild type & 63 & 14 & 77 \\
p53 mutation & & 4 & 21 \\
& 17 & 18 & 98
\end{tabular}

$\chi^{2}$ test: $P>0.999^{\star}$ Tumor DNA was suitable for both analyses in 98 of the 116 patients ${ }^{\star \star}$ Bax-frameshift mutations were detected by fragment-length analysis of the $\mathrm{G}(8)$ tract in exon $3^{\star \star \star} \mathrm{P} 53$ mutations were analyzed by SSCP-PCR of exons 5-8

impact of p53 mutation on survival in the Bax-mutated patients (Figure 3a). Patients with tumors carrying both a mutation of the Bax gene and a p53 mutation showed an early relapse after surgery and rapidly succumbed to the disease. In contrast, patients with Bax-mutated but p53 wild-type tumors had an excellent prognosis and survival reaches a plateau of survival at $76 \%$ at 4 years after surgery. Figure $3 b$ shows that p53 does not have any impact on survival in the Bax wild-type cohort. In addition, the small difference in overall survival as seen in Figure $2 b$ is not present when comparing the p53 status in the Bax wild-type cohort.

\section{Analysis for MSI}

The microsatellite markers BAT-25 and BAT-26 identify with high specificity tumors expressing high-frequency MSI. ${ }^{27-29}$ To determine the linkage of Bax-frameshift mutations to high MSI and global MMR deficiency, we perfomed a PCR fragment-length analysis for BAT-25 and BAT-26. Informative results were obtained in 113 of the 116 tumors and eight tumors $(6.9 \%)$ were identified as microsatellite instable, which is in line with frequencies for BAT-25/BAT-26 microsatellite instable tumors as reported by other groups. ${ }^{28,30}$ No p53 mutations could be detected in these eight tumors confirming that both events, p53 mutation and MMR deficiency, are related to different pathways of tumorigenesis and tumor progression. ${ }^{31}$ The BAT-25/BAT-26 microsatellite instable tumors showed a slightly better overall survival, which, however, did not reach the level of statistical significance (Cox-Mantel log-rank test, $P=0.26$ ). Bax-frameshift analysis and BAT-25/BAT-26 mutation data were both available for 97 of the 116 patients. Contingency table testing revealed that Bax mutations do not cluster in the subgroup of tumors displaying high $\mathrm{MSI}\left(\chi^{2}\right.$ test: $P>0.99$; Table 3$)$. This indicates that Bax mutations are related either to a mutator genotype with low MSI or may even arise sporadically, independent of MMR deficiency.

\section{Discussion}

The disruption of apoptotic pathways is a critical event in tumorigenesis and disease progression. In previous studies, we demonstrated that the loss of Bax in consequence of disturbed transcriptional control and protein expression is related to an impaired response to anticancer therapy and poor prognosis in esophageal and colorectal carcinoma. ${ }^{13-15}$
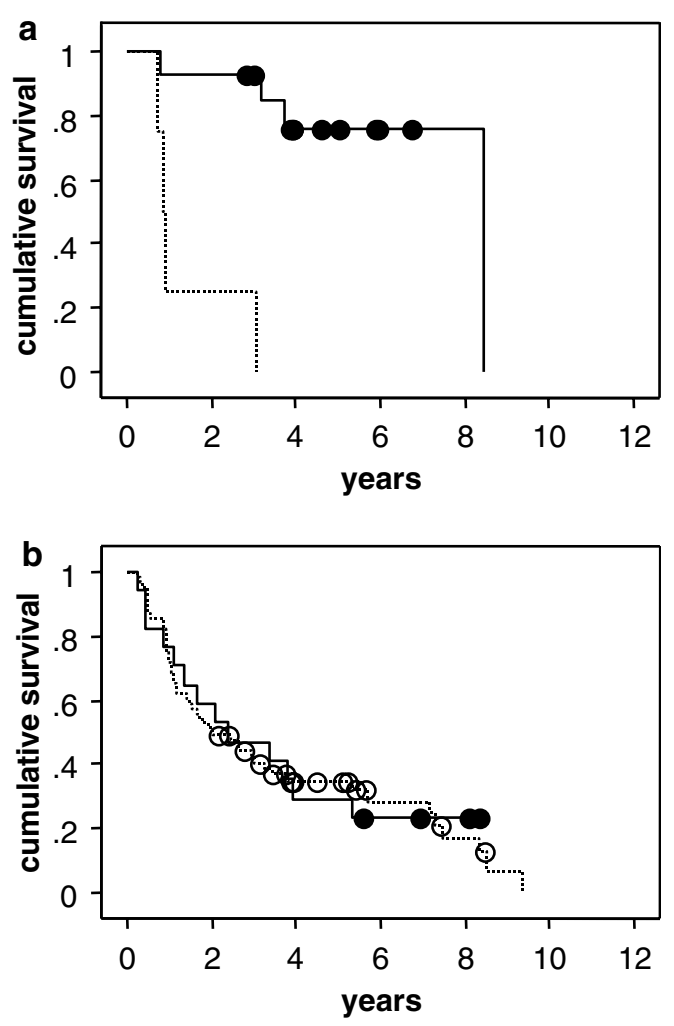

Figure 3 Combined analysis of Bax and p53 mutation. Patients were grouped in p53-mutated (open circles, broken line) versus p53 wild-type tumors (black circles, continuous line). (a) Kaplan-Meier analysis of patients with Baxframeshift mutated tumors (log-rank (Mantel-Cox) test: $P<0.0001)$. (b) KaplanMeier analysis of patients with Bax wild-type tumors (log-rank (Mantel-Cox) test: $P=0.96)$. Log-rank (Mantel-Cox) test for all four groups (3 degrees of freedom): $P=0.004$

Table 3 Relation of Bax and global MSI*

\begin{tabular}{lccr} 
& Bax wild type & Bax mutation ** & Total \\
\hline MSI negative & 74 & 16 & 90 \\
MSI positive *** & 6 & 1 & 7 \\
& 80 & 17 & 97
\end{tabular}

$\chi^{2}$ test: $P>0.999^{\star}$ Tumor DNA was suitable for both analyses in 97 of the 116 patients ${ }^{\star *}$ Bax-frameshift mutations were detected by fragment-length analysis of the $\mathrm{G}(8)$ tract in exon $3^{\star * *}$ Global mismatch repair deficiency/MSI was determined by fragment-length analysis of BAT-25 and BAT-26 microsatellites

Gastric cancer is extremely refractory to cytotoxic anticancer therapies. In comparison to other gastroenterological tumors, prognosis is especially poor and relapse after surgery is common. Nevertheless, the role of disruption of Bax and other apoptosis regulators in this disease entity remained poorly defined. To this end, we retrospectively analyzed the expression and mutation of Bax and of p53, a transcriptional activator of the Bax gene, in 116 patients with gastric cancer, who underwent tumor resection with curative intent.

To our surprise, we found that gastric carcinoma patients with loss of Bax expression paradoxically presented with a 
slightly better prognosis. Mutational analysis of Bax revealed that loss of Bax occurs in consequence of a frameshift mutation in the $\mathrm{G}(8)$ tract of the Bax gene being significantly associated with a better overall survival. This finding would be well in line with a MMR-deficient genotype of these patients, which in turn, is known to be associated with a better disease prognosis. The analysis of global MMR deficiency by testing for frameshifts in the BAT-25 and BAT-26 microsatellites revealed, however, that Bax-frameshift mutations are not related to a highly microsatellite instable genotype reflecting global MMR deficiency. This suggests that Bax-frameshift mutations may occur sporadically also in tumors with low MSI, which could explain the lower frequencies of Bax-frameshift mutations (25-60\%) previously described in BAT-25/BAT-26 microsatellite instable tumors. ${ }^{28,32}$ Bax-frameshift mutations may reflect a high spontaneous mutation rate, the mitotic history of the tumor and the clonal expansions occurring during tumorigenesis and tumor progression. ${ }^{33}$ In addition, such mutations in the Bax gene may confer a selection advantage, which led to the hypothesis that inactivation of Bax in MMR-deficient tumors represents a late event related to disease progression. ${ }^{23}$ Given their good prognosis, such tumors could share not only a different tumor biology but also a different disease pathogenesis. Thus, in view of our present data, Bax-frameshift mutation could be a key feature of tumors with low MSI.

In contrast, concomitant mutation of p53 is rarely observed in MMR-deficient gastric cancer. ${ }^{28}$ This is supported by our present observation that none of the BAT-25/BAT-26 microsatellite instable tumors displayed a p53 mutation. During gastric carcinogenesis, p53 disruption is known to be associated with progression from intestinal metaplasia to dysplasia. $^{34,35}$ Sporadic gastric carcinomas frequently show alterations of the p53 gene, either by mutation or allelic loss. This is in clear contrast to the low frequency of p53 inactivation in microsatellite instable colorectal ${ }^{36,37}$ and gastric carcinomas. ${ }^{28}$ Thus, it is not surprising that no clear data are available regarding the role of p53 mutation in mismatch-deficient tumors of the gastrointestinal tract.

The present study is the first report to show that the combined inactivation of p53 in Bax-mutated tumors results in early relapse and disastrous survival. In contrast, tumors with Bax-frameshift mutation but p53 wild type have a rather good prognosis. Notably, inactivation of p53 in Bax wild-type tumors did not affect prognosis. Contingency table testing demonstrates that mutation of p53 and Bax are statistically independent events. The reasons for this are unknown. Possibly, the single inactivation of either Bax or p53 can be compensated for because of the activities of redundant homologs, that is, Bak or p63/p73. The concomitant inactivation of two key regulators acting consecutively could, however, be sufficient to functionally disrupt apoptosis signaling.

In this line, it is not surprising that the role for p53 as negative prognostic indicator in gastric cancer has been discussed controversially. ${ }^{38-41}$ Inactivation of p53 may result in an aggressive type of gastric cancer with early infiltration of the submucosa. ${ }^{42}$ In the present study, both isolated p53 mutation and p53 overexpression were not associated with differences in disease prognosis. Thus, in consideration of our data, the deleterious effect of inactivation of p53 as described in several studies in gastric cancer might be an epiphenomenon, which depends on the inactivation of Bax, as shown in this study, or disruption of other regulatory genes.

Our findings thereby support the notion that gastric carcinomas are biologically heterogeneous and may arise in part through different mechanisms. Future studies will reveal if such good or poor prognostic subgroups may also benefit from aggressive adjuvant cytotoxic therapies.

\section{Materials and Methods}

\section{Patients}

A total of 116 patients with curatively intended R0-resection of gastric carcinoma from a single institution (Department of General and Vascular Surgery, University Hospital, Frankfurt, Germany) were analyzed. Surgery was performed between 1986 and 1996. No patient received preoperative chemo- or radiotherapy. Actual follow-up data concerning survival were assessed with the help of the patients' general care physicians and the official administration department. Clinicopathological informations are given in Table 1.

\section{Immunohistochemistry for Bax and p53}

For protein detection by immunohistochemistry, $4 \mu \mathrm{m}$ slices of paraffinembedded tissue were stained as described previously. ${ }^{14,15,24}$ Murine monoclonal antibodies against Bax (clone YTH-2D2, Trevigen Inc., MD, USA, dilution $1: 750$ ) or p53 (clone DO-7, Dako, Denmark, dilution 1:75) were employed. A blinded approach was used for slide analysis. Four high-power fields $(\times 400)$ were evaluated for percentage of positive cells $(0-100 \%$ in $5 \%$ steps for Bax and p53) and staining intensity (negative to strongly positive, categorized in integer values from 0 to 3 ). From the staining intensity and the percentage of positive cells, we calculated the product, which is expressed as staining index (SI). In addition, we compared the SI as measure for protein expression with the 'percentage of stained tumor cells' in all analyses.

\section{Mutation analysis of p53}

DNA was extracted from $30 \mu \mathrm{m}$ slices of paraffin-embedded tissue. Extraction of genomic DNA was done after deparaffination (n-octane) and rehydration using the Invisorb Spin Tissue Kit (Invitek, Berlin, Germany). For storage, the DNA was eluted in $10 \mathrm{mM}$ Tris-HCl/0.1 mM EDTA buffer (pH 8.7). p53 Mutations in the DNA binding region were detected by SSCP-PCR (single-strand conformational polymorphism) analyses. Precise description and primer sequences for exons 5-7 of the method are given elsewhere. ${ }^{14}$ For exon eight the primers were modified (sense: CCT TAC TGC CTC TTG CTT $C$ and antisense: GGC ATA ACT GCA CCC TTG G, $94^{\circ} \mathrm{C}$ followed by 35 cycles at $94^{\circ} \mathrm{C}$ for $30 \mathrm{~s}, 55^{\circ} \mathrm{C}$ for $20 \mathrm{~s}$, $72^{\circ} \mathrm{C}$ for $20 \mathrm{~s}$ ). Briefly, exons 5-8 of the DNA binding domain of the p53 gene were amplified, and for SSCP analysis, $5 \mu \mathrm{l}$ of the amplified fragments were diluted in $7 \mu$ l loading buffer ( $82 \%$ formamide, $10 \mathrm{mmol} / \mathrm{l}$ $\mathrm{NaOH}, 50 \mathrm{mmol} / \mathrm{EDTA}$, bromophenol blue, xylene xyanole dye). The samples were denatured at $95^{\circ} \mathrm{C}$ for $5 \mathrm{~min}$ and cooled on ice. The denatured fragments were analyzed on a $10 \%$ nondenaturing polyacrylamide gel at $500 \mathrm{~V}$ and $50 \mathrm{~mA}$ for $2 \mathrm{~h}$ at $10^{\circ} \mathrm{C}$ for exons 5,7 and 8 and at $22^{\circ} \mathrm{C}$ for exon 6 in a Multiphor electrophoresis chamber (Pharmacia, Freiburg, Germany) and were subsequently visualized by silver staining. 


\section{Bax-frameshift mutations}

A 94 bp fragment of the Bax exon 3 encompassing the $G(8)$ tract was amplified by PCR using primer sequences and cycling conditions as described previously. ${ }^{14}$ Taq polymerase (Invitek, Berlin, Germany) was used and the reversed primer was labeled with the $A B I$ fluorescence dye HEX. PCR fragment length was analyzed on a ABI 310 Sequencer (Perkin Elmer Cetus, Weiterstadt, Germany) and compared to an internal size standard. As positive control the human colon carcinoma cell line LoVo was used, which carries mutations in both Bax alleles: one shows an insertion $(G(9))$, the other a deletion $(G(7))$ in the $G(8)$ tract. $^{23}$ The human colon carcinoma cell line SW 620 served as wild-type control. In dilution experiments, the sensitivity (cutoff: 10\% mutated cells) and in blinded experiments the specificity (100\%) of the fragment-length analysis were confirmed.

\section{Analysis for MSI}

BAT-25 and BAT-26 microsatellites were analyzed by fragment-length polymorphism analysis as described ${ }^{30}$ to identify patients with highfrequency (global) MSI. ${ }^{27}$

\section{Statistical analysis}

Overall survival was estimated by the Kaplan-Meier product-limit method, starting from the time of surgery. The survival curves were compared by the means of the Mantel-Cox log-rank test. As 'normal values' for gastric cancer are not known for Bax and p53 protein expression, we employed the same cutoff points as employed in a previous study, that is, $10 \%$ positive cells. ${ }^{14}$ Expression-values above or equal to cutoff points were considered as positive, those below the cutoff values were considered as negative staining. In parallel, we analyzed the staining indices for Bax and p53 as described above which yielded results comparable to the analysis of the percentages of positively stained tumor cells.

\section{Acknowledgments}

We wish to thank Jana Rossius for expert technical assistance. This work was supported by the Deutsche Forschungsgemeinschaft research task forces SFB 506 and grant Da 234/4-1.

\section{References}

1. Stadtlander CT and Waterbor JW (1999) Molecular epidemiology pathogenesis and prevention of gastric cancer. Carcinogenesis 20: 2195-2208

2. Neugut Al, Hayek M and Howe G (1996) Epidemiology of gastric cancer. Semin. Oncol. 23: 281-291

3. Black RJ, Bray F, Ferlay J and Parkin DM (1997) Cancer incidence and mortality in the European union: cancer registry data and estimates of national incidence for 1990. Eur. J. Cancer. 33: 1075-1107

4. Fuchs CS and Mayer RJ (1995) Gastric carcinoma. N. Engl. J. Med. 333: 32-41

5. Bargou RC, Daniel PT, Mapara MY, Bommert K, Wagener C, Kallinich B, Royer HD and Dörken B (1995) Expression of the bcl-2 gene family in normal and malignant breast tissue: low bax-alpha expression in tumor cells correlates with resistance towards apoptosis. Int. J. Cancer 60: 854-859

6. Bargou RC, Wagener C, Bommert K, Mapara MY, Daniel PT, Arnold W, Dietel M, Guski H, Feller A, Royer HD and Dörken B (1996) Overexpression of the death-promoting gene bax-alpha which is downregulated in breast cancer restores sensitivity to different apoptotic stimuli and reduces tumor growth in scid mice. J. Clin. Invest. 97: 2651-2659
7. Bosanquet, Sturm I, Wieder T, Essmann F, Margaret I, Bosanquet M, Head DJ, Dörken B and Daniel PT (2001) Bax expression correlates with cellular drug sensitivity to doxorubicin, cyclophosphamide and chlorambucil but not fludarabine, cladribine or corticosteroids in B cell chronic lymphocytic leukemia. Leukemia 16: 1035-1044

8. Hemmati PG, Gillissen B, von Haefen C, Wendt J, Stärck L, Güner D, Dörken B and Daniel PT (2002) Adenovirus-mediated overexpression of p14arf induces p53 and bax-independent apoptosis. Oncogene 21: 3149-3161

9. von Haefen C, Wieder T, Gillissen B, Stärck L, Graupner V, Dörken B and Daniel PT (2002) Ceramide induces mitochondrial activation and apoptosis via a bax-dependent pathway in human carcinoma cells. Oncogene 21: 4009-4019

10. Radetzki S, Köhne $\mathrm{CH}$, von Haefen C, Gillissen B, Sturm I, Dörken B and Daniel PT (2002) The apoptosis promoting bcl-2 homologues bak and nbk/bik overcome drug resistance in mdr-1-negative and mdr-1 overexpressing breast cancer cell lines. Oncogene 21: 227-238

11. Krajewski S, Blomqvist C, Franssila K, Krajewska M, Wasenius VM, Niskanen E, Nordling S and Reed JC (1995) Reduced expression of proapoptotic gene bax is associated with poor response rates to combination chemotherapy and shorter survival in women with metastatic breast adenocarcinoma. Cancer Res. 55: 4471-4478

12. Tai YT, Lee S, Niloff E, Weisman C, Strobel T and Cannistra SA (1998) Bax protein expression and clinical outcome in epithelial ovarian cancer. J. Clin. Oncol. 16: 2583-2590

13. Schelwies K, Sturm I, Grabowski P, Scherübl H, Schindler I, Hermann S, Stein H, Buhr HJ, Riecken EO, Zeitz M, Dörken B and Daniel PT (2002) Analysis of p53/bax in primary colorectal carcinoma: low bax protein expression is a negative prognostic factor in uicc stage I tumors. Int. J. Cancer. 99: 589-596

14. Sturm I, Kohne $\mathrm{CH}$, Wolff G, Petrowsky H, Hillebrand T, Hauptmann S, Lorenz M, Dörken B and Daniel PT (1999) Analysis of the p53/bax pathway in colorectal cancer: Low bax is a negative prognostic factor in patients with resected liver metastases. J. Clin. Oncol. 17: 1364-1374

15. Sturm I, Petrowsky H, Volz R, Lorenz M, Radetzki S, Hillebrand T, Wolff G, Hauptmann S, Dörken B and Daniel PT (2001) Analysis of p53/bax/p16ink4a/ cdkn2 in esophageal squamous cell carcinoma: high bax and p16ink4a/cdkn2 identifies patients with good prognosis. J. Clin. Oncol. 19: 2272-2281

16. Friess H, Lu Z, Graber HU, Zimmermann A, Adler G, Korc M, Schmid RM and Büchler MW (1998) Bax, but not bcl-2, influences the prognosis of human pancreatic cancer. Gut 43: 414-421

17. Prokop A, Wieder T, Sturm I, Essmann F, Seeger K, Wuchter C, Ludwig W-D, Henze G, Dörken B and Daniel PT (2000) Relapse in childhood acute lymphoblastic leukemia is associated with decrease of bax/bcl-2-ratio and loss of spontaneous caspase-3 processing in vivo. Leukemia 14: 1606-1613

18. Miyashita T and Reed JC (1995) Tumor suppressor p53 is a direct transcriptional activator of the human bax gene. Cell 80: 293-299

19. Benchimol S (2001) P53-dependent pathways of apoptosis. Cell Death Differ. 8: 1049-1051

20. Wang JY (2001) DNA damage and apoptosis. Cell Death Differ. 8: 1047-1048

21. Puthalakath $H$ and Strasser $A$ (2002) Keeping killers on a tight leash: transcriptional and post-translational control of the pro-apoptotic activity of B4-only proteins. Cell Death Differ. 9: 505-512

22. Hermann S, Sturm I, Mrozek A, Klosterhalfen B, Hauptmann S, Dörken B and Daniel PT (2001) Bax expression in benign and malignant thyroid tumors: dysregulation of wild type p53 is associated with a high bax and p21 expression in thyroid carcinoma. Int. J. Cancer 92: 805-811

23. Rampino N, Yamamoto H, Ionov Y, Li Y, Sawai H, Reed JC and Perucho M (1997) Somatic frameshift mutations in the bax gene in colon cancers of the microsatellite mutator phenotype. Science 275: 967-969

24. Sturm I, Papadopoulos S, Hillebrand T, Benter T, Lück H-J, Wolff G, Dörken B and Daniel PT (2000) Impaired bax protein expression in breast cancer: mutational analysis of the bax and the p53 gene. Int. J. Cancer 87: 517-521

25. Yamamoto $\mathrm{H}$, Perez-Piteira J, Yoshida T, Terada M, Itoh F, Imai $\mathrm{K}$ and Perucho M (1999) Gastric cancers of the microsatellite mutator phenotype display characteristic genetic and clinical features. Gastroenterology 116: 1348-1357

26. dos Santos NR, Seruca R, Constancia M, Seixas M and Sobrinho-Simoes M (1996) Microsatellite instability at multiple loci in gastric carcinoma: clinicopathologic implications and prognosis. Gastroenterology 110: 38-44 
27. Boland CR, Thibodeau SN, Hamilton SR, Sidransky D, Eshleman JR, Burt RW, Meltzer SJ, Rodriguez-Bigas MA, Fodde R, Ranzani GN and Srivastava S (1998) A National Cancer Institute Workshop on microsatellite instability for cancer detection and familial predisposition: development of international criteria for the determination of microsatellite instability in colorectal cancer. Cancer Res. 58: 5248-5257

28. lacopetta BJ, Soong R, House AK and Hamelin R (1999) Gastric carcinomas with microsatellite instability: clinical features and mutations to the tgf-beta type ii receptor, igfii receptor, and bax genes. J. Pathol. 187: 428-432

29. Stone JG, Tomlinson IP and Houlston RS (2000) Optimising methods for determining rer status in colorectal cancers. Cancer Lett. 149: $15-20$

30. Zhou XP, Hoang JM, Li YJ, Seruca R, Carneiro F, Sobrinho-Simoes M, Lothe RA, Gleeson CM, Russell SE, Muzeau F, Flejou JF, Hoang-Xuan K, Lidereau R, Thomas $G$ and Hamelin R (1998) Determination of the replication error phenotype in human tumors without the requirement for matching normal DNA by analysis of mononucleotide repeat microsatellites. Genes Chromosomes Cancer 21: 101-107

31. Strickler JG, Zheng J, Shu Q, Burgart LJ, Alberts SR and Shibata D (1994) P53 mutations and microsatellite instability in sporadic gastric cancer: when guardians fail. Cancer Res. 54: 4750-4755

32. Yamamoto $\mathrm{H}$, Itoh $\mathrm{F}$, Fukushima $\mathrm{H}$, Adachi $\mathrm{Y}$, Itoh $\mathrm{H}$, Hinoda $\mathrm{Y}$ and Imai $\mathrm{K}$ (1999) Frequent bax frameshift mutations in gastric cancer with high but not low microsatellite instability. J. Exp. Clin. Cancer Res. 18: 103-106

33. Perucho M (1999) Correspondence re: C.R. Boland et al., a National Cancer Institute Workshop on microsatellite instability for cancer detection and familial predisposition: development of international criteria for the determination of microsatellite instability in colorectal cancer. Cancer Res, 58: 5248-5257, 1998. Cancer Res. 59: 249-256
34. Gomyo Y, Osaki M, Kaibara $\mathrm{N}$ and Ito $\mathrm{H}$ (1996) Numerical aberration and point mutation of p53 gene in human gastric intestinal metaplasia and welldifferentiated adenocarcinoma: analysis by fluorescence in situ hybridization (fish) and pcr-sscp. Int. J. Cancer 66: 594-599

35. Shiao YH, Rugge M, Correa P, Lehmann HP and Scheer WD (1994) P53 alteration in gastric precancerous lesions. Am. J. Pathol. 144: 511-517

36. Cottu PH, Muzeau F, Estreicher A, Flejou JF, Iggo R, Thomas G and Hamelin R (1996) Inverse correlation between rer+ status and p53 mutation in colorectal cancer cell lines. Oncogene 13; 2727-2730

37. Konishi M, Kikuchi-Yanoshita R, Tanaka K, Muraoka M, Onda A, Okumura Y, Kishi N, Iwama T, Mori T, Koike M, Ushio K, Chiba M, Nomizu S, Konishi F, Utsunomiya $\mathrm{J}$ and Miyaki M (1996) Molecular nature of colon tumors in hereditary nonpolyposis colon cancer, familial polyposis, and sporadic colon cancer. Gastroenterology 111: 307-317

38. Lee WJ, Shun CT, Hong RL, Wu MS, Chang KJ and Chen KM (1998) Overexpression of p53 predicts shorter survival in diffuse type gastric cancer. Br. J. Surg. 85: 1138-1142

39. Allgayer H, Heiss MM and Schildberg FW (1997) Prognostic factors in gastric cancer. Br. J. Surg. 84: 1651-1664

40. Lim BH, Soong R, Grieu F, Robbins PD, House AK and lacopetta BJ (1996) P53 accumulation and mutation are prognostic indicators of poor survival in human gastric carcinoma. Int. J. Cancer 69: 200-204

41. Victorzon M, Nordling S, Haglund C, Lundin J and Roberts PJ (1996) Expression of $\mathrm{p} 53$ protein as a prognostic factor in patients with gastric cancer. Eur. J. Cancer 32A: 215-220

42. Ranzani GN, Luinetti O, Padovan LS, Calistri D, Renault B, Burrel M, Amadori D, Fiocca R and Solcia E (1995) P53 gene mutations and protein nuclear accumulation are early events in intestinal type gastric cancer but late events in diffuse type. Cancer Epidemiol. Biomarkers Prev. 4: 223-231 